\title{
Testicular aspiration biopsy in evaluation of fertility of mink (Mustela vison)
}

\author{
C. Sundqvist, A. Lukola* and M. Parvinen $\dagger$ \\ Departments of Biology and of * Biochemistry \& Pharmacy, Abo Akademi, Porthansgatan $3 B$, \\ SF-20500 Turku, and $\dagger$ Institute of Biomedicine, Department of Anatomy, University of Turku, \\ Kiinamyllynkatu 10, SF-20500 Turku, Finland
}

\begin{abstract}
Summary. A 19-gauge needle biopsy was taken of the testis of mink in late January. When scores from 1 to 10 were given according to the developmental stage and number of spermatogenic cells, males scoring $8-10$ returned significantly better breeding results than did males having scores $<7$. The biopsy did not affect libido or induce other disturbances of fertility. Fine-needle aspiration biopsy of the testis is possibly the most convenient and accurate infertility assay in mink breeding.
\end{abstract}

\section{Introduction}

Mink breeding success is greatly affected by the presence of infertile males: up to $20 \%$ of males are commonly found to be infertile during the sexually active period (Tung, Ellis, Childs \& Dufau, 1984). So that such males can be eliminated from breeding groups, infertility has been assessed by using testicular palpation (Onstad, 1967), microscopical evaluation of vaginal sperm smears (Onstad, 1967; Sundqvist \& Gustafsson, 1983) and by using a serum testosterone test (Sundqvist, Lukola \& Valtonen, 1984).

As mink are seasonal breeders they exhibit a cyclicity in testicular development. Spermatogenesis is completed 2 months before the mating season, which is restricted to 2 or 3 weeks in March (Onstad, 1967), and maximal information on the testicular development can therefore be obtained between late January and late March.

The purpose of this investigation was to evaluate a new technique, fine-needle aspiration biopsy of the testis, as complementary to the hitherto available test methods.

\section{Materials and Methods}

Animals. The 1-year-old animals $(\mathrm{N}=200)$ used in this investigation in late January were of a dark colour type and originated from Kimito Mink Co., a conventional mink farm located in south-west Finland. Animals were exposed to natural weather and daylight conditions and were fed a standard wet diet provided by a central food kitchen. Additionally, 87 males of the same colour type were randomly chosen from 2 nearby mink houses on the same farm to serve as a non-biopsied control group, and they were treated in the same way as the biopsied animals.

Collection of specimens. Under palpation control, the testes of unanaesthetized mink were punctured by a 19-gauge needle, carefully avoiding any injury to the cauda epididymidis. A slight pressure was produced and the samples obtained were spread onto object glasses, air-dried and analysed after staining with a May-Grünwald-Giemsa solution.

Analysis of mink fertility. To evaluate quantitatively the quality of the specimen, we used a slightly modified Johnsen's score count (Johnsen, 1970): 1, Sertoli cells only; 2, spermatogonia 
only; 3 and 4 , no further than primary spermatocytes $(<10$ and $10-30$ spermatocytes per view respectively); 5,6 and 7 , no further than round spermatids $(<10,10-40$ and $>40$ spermatids per view respectively); 8, 9 and 10 , maturation phase spermatids $(<20,20-50$ and $>50$ spermatids per view respectively).

As a rule more than 40 randomly selected views were evaluated using $\times 400$ magnification and a mean biopsy score count was calculated for each male. In most cases a biopsy was taken from one testis only. If differences in size were found, the larger testis was biopsied. All samples were collected during I day in late January.

\section{Results}

From the 200 mink males analysed by fine-needle aspiration biopsy, 5 failed to mate and 7 males died before the mating season. Two specimens were accidentally destroyed. In the control group $(\mathrm{N}=87) 2$ males failed to mate and 8 males died before the mating season.

When points (1-10) were awarded for the distribution of the spermatogenic cells in the testis specimen for each male, individual differences were apparent. In Fig. 1, individual biopsy score counts are compared with the number of kits produced per mated female. There was a tendency $(P<0.05)$ for high scoring males to return better breeding results, as seen also in Table 1. Arranging

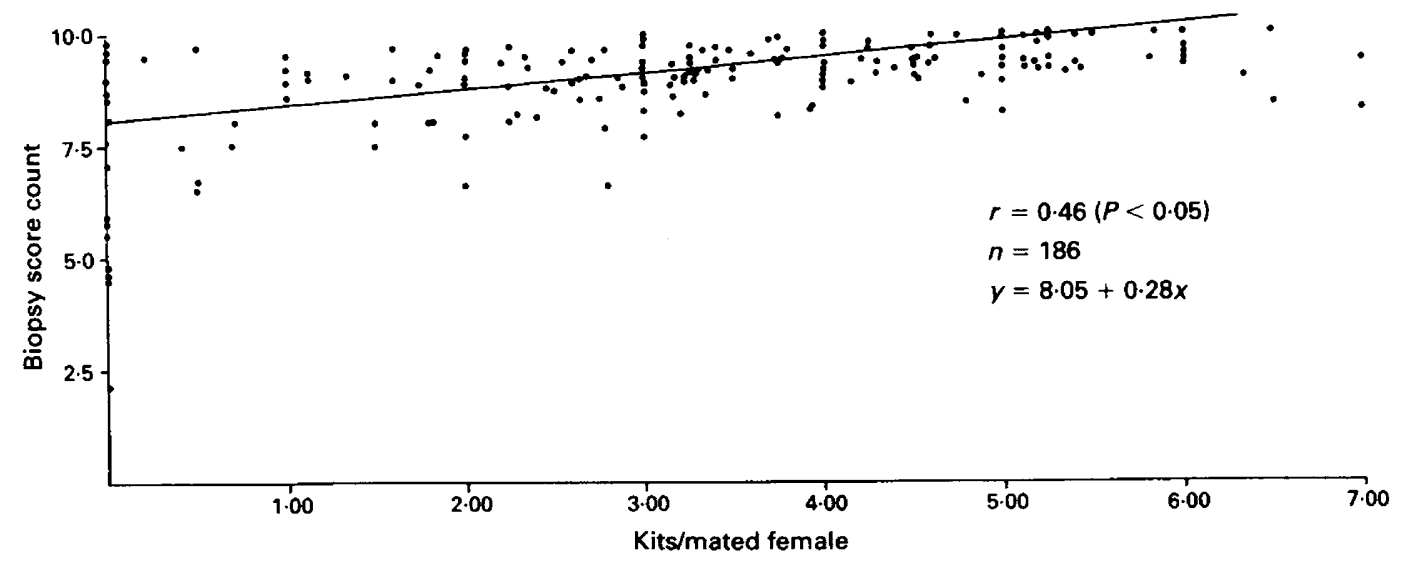

Fig. 1. Relationship between individual testicular biopsy score counts and reproductive results in mink.

Table 1. Mink male reproduction results after performance of fine-needle aspiration biopsy of testes

\begin{tabular}{|c|c|c|c|c|c|}
\hline $\begin{array}{l}\text { Biopsy } \\
\text { score } \\
\text { count }\end{array}$ & $\begin{array}{l}\text { No. of } \\
\text { males }\end{array}$ & $\begin{array}{l}\text { No. of } \\
\text { females } \\
\text { mated }\end{array}$ & $\begin{array}{c}\text { No of } \\
\text { females } \\
\text { pregnant }\end{array}$ & $\begin{array}{c}\% \text { females } \\
\text { not } \\
\text { pregnant }\end{array}$ & $\begin{array}{l}\text { No. of kits } \\
\text { per mated } \\
\text { female }\end{array}$ \\
\hline 10 & 45 & $4 \cdot 7 \pm 1 \cdot 5$ & $3.6 \pm 1.8$ & $25 \cdot 6 \pm 28 \cdot 7$ & $3 \cdot 3 \pm 1 \cdot 6$ \\
\hline 9 & 108 & $4.9 \pm 1.8$ & $3.6 \pm 1.9$ & $27.8 \pm 28.8$ & $3.3 \pm 1.6$ \\
\hline 8 & 21 & $4.6 \pm 1.5$ & $3 \cdot 3 \pm 1 \cdot 1$ & $25 \cdot 1 \pm 20 \cdot 9$ & $2.9 \pm 1.9$ \\
\hline 7 & 5 & $4.4 \pm 1.8$ & $1 \cdot 4 \pm 1 \cdot 5^{* *}$ & $64 \cdot 0 \pm 30 \cdot 9^{* *}$ & $1 \cdot 2 \pm 1 \cdot 2^{* *}$ \\
\hline 6 & 3 & $3 \cdot 0 \pm 2 \cdot 0$ & $0.0 \pm 0.0^{* *}$ & $100 \cdot 0 \pm 0 \cdot 0^{* *}$ & $0.0 \pm 0.0^{* *}$ \\
\hline 5 & 3 & $1 \cdot 3 \pm 0.6^{* *}$ & $0 \cdot 0 \pm 0.0^{* *}$ & $100 \cdot 0 \pm 0.0^{* *}$ & $0.0 \pm 0.0^{* *}$ \\
\hline 2 & 1 & $2.0 \pm 0.0$ & $0.0 \pm 0.0$ & $100.0 \pm 0.0^{*}$ & $0.0 \pm 0.0$ \\
\hline - & 77 & $4.8 \pm 1 \cdot 8$ & $3 \cdot 1 \pm 2 \cdot 1$ & $37 \cdot 0 \pm 35 \cdot 3$ & $2 \cdot 9 \pm 2.0$ \\
\hline
\end{tabular}

${ }^{*} P<0.05,{ }^{*} P<0.01$ compared with males giving biopsy score counts $=10$ (single classification random ANOVA). Values are mean \pm s.e.m. 

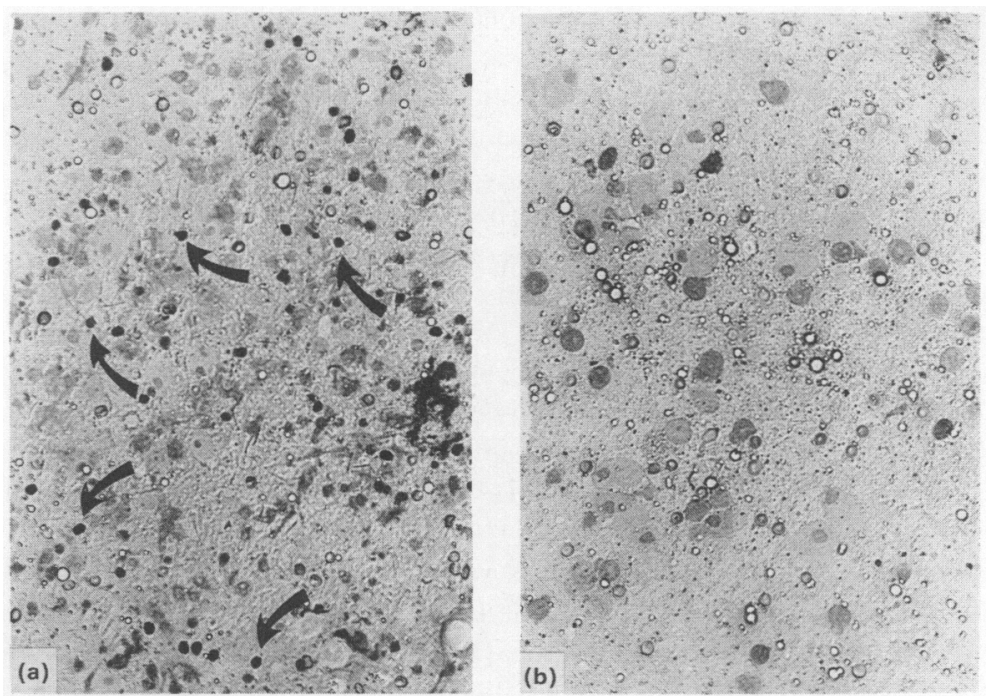

Fig. 2. Representative pictures of fine-needle aspiration biopsy of testes of mink. (a) Note the presence of maturation-phase spermatids (arrows). (b) No maturation-phase spermatids are present. May-Grünwald-Giemsa. $\times 450$.

Table 2. A comparison between non-biopsied and biopsied groups of male mink regarding their reproductive performance

\begin{tabular}{lccccc}
\hline Males & $\begin{array}{c}\text { No. of } \\
\text { males }\end{array}$ & $\begin{array}{c}\text { No. of } \\
\text { females } \\
\text { mated }\end{array}$ & $\begin{array}{c}\text { No. of } \\
\text { females } \\
\text { pregnant }\end{array}$ & $\begin{array}{c}\% \text { females } \\
\text { not } \\
\text { pregnant }\end{array}$ & $\begin{array}{c}\text { No. of kits } \\
\text { per mated } \\
\text { female }\end{array}$ \\
\hline $\begin{array}{l}\text { Non-biopsied } \\
\text { Biopsied }\end{array}$ & 77 & $4.8 \pm 1.8$ & $3.1 \pm 2.1$ & $37.0 \pm 35 \cdot 3$ & $2.9 \pm 2.0$ \\
\hline
\end{tabular}

Values are mean \pm s.e.m.

males in groups according to their individual biopsy score counts revealed that males scoring $<7$ could be considered as infertile.

Representative cytologies of testicular biopsies are seen in Fig. 2. The main emphasis was focussed on the presence of condensing acrosome- and maturation-phase spermatids, and on the presence of haploid germ cells. In animals with complete spermatogenesis the number of maturationphase spermatids varied. No significant differences $(P=0 \cdot 14-0 \cdot 61$, Student's $t$ test $)$ could be seen in any measurement for the biopsied and non-biopsied males (Table 2).

\section{Discussion}

Since its introduction (Charny, 1940; Hotchkiss, 1942), surgical biopsy has remained the most accurate method for assessing the pathogenesis of male infertility (Wong, Straus \& Warner, 1973; Levin, 1979; Leong \& Matthews, 1982). Testicular biopsies have also been taken by the aspiration technique for cytological examination of infertile men, and complete agreement between cytology and histology has been reported (Persson, Åhren \& Obrant, 1971; Nseyo, Englander, Huben \& Pontes, 1984). 
As could be seen from the reproductive performance of biopsied male mink no harmful effects on libido or general behaviour were observed. Due to the severe winter (temperatures ranging from -15 to $-27^{\circ} \mathrm{C}$ over a period of 4 weeks in January-February) 7 mink being biopsied died before the mating season. As untreated mink in the vicinity also died, the reason for death could not be solely attributable to the biopsy procedure.

The extremely dark colour variety of mink has been shown to produce antisperm antibodies (Tung et al., 1981) and there might also be a risk of such reactions in other colour varieties. Puncturing the testis with a needle might destroy the blood-testis barrier, thereby permitting autosensitization to the mink's own spermatids and spermatozoa (Tung \& Alexander, 1977). Our results show that autoimmunization possibiy had not time to develop in mink during the 2 months after sample collection. Males scoring 8-10 were of significantly better fertility than were those in the non-biopsied population. We have recently successfully used smaller needles (20- and 22-gauge) to collect cells, thus interfering with the testes as little as possible. It must be emphasized that most male mink are used only once for breeding.

Information about the spermatid number is valuable when searching for mink with affected spermatogenesis as variations in spermatogenesis at any point should also be reflected in a corresponding change in the spermatid numbers (Berndtson, 1977). Although the quantitation of spermatids in our work was subjective, males having the greatest number of maturation-phase spermatids also generally showed better reproduction results than did males with biopsy score counts of 8 instead of 9 or 10 . This difference did not, however, reach the level of significance. There is evidence suggesting that some seminiferous tubules might exhibit more active spermatogenesis than others (Onstad, 1967; Colgan, Bedard, Strawbridge, Buckspan \& Klotz, 1980). These difficulties were eliminated as far as possible by moving the needle within the testis to collect cells from a larger area.

The mink reproduction results show that although the males with biopsy scores of $8-10$ had been assessed as being fully fertile, more than $20 \%$ of the females failed to produce young. In former investigations using the sperm test the percentage of non-pregnant females declined from 25 to 18 (Sundqvist \& Gustafsson, 1983) after elimination of males producing poor quality spermatozoa. In the dark colour type of mink the effect of elimination of infertile males was less significant than in other types, giving rise to the speculation that the poor reproduction results in dark mink may be mainly a female effect. According to the present investigation $6.5 \%$ of the males should have been eliminated from breeding (biopsy score count 2-6), as being infertile. In colour types in which the proportion of infertile males is greater, i.e. the sapphire or black-cross (Sundqvist \& Gustafsson, 1983; Tauson, 1985), the usefulness of aspiration biopsy assay should be greater. The possibility of rating fertile males by biopsy score counts from 8 to 10 gives the farmer a better chance to improve the usage of good males for breeding than do other presently available fertility tests.

The most convenient male mink infertility assay seems to be the fine-needle aspiration biopsy of the testis, as it can be performed with great accuracy from late January until late March. The aspiration biopsy assay should therefore be the method of choice for fur farmers trying to eliminate poor reproduction results.

Part of this research has been financed by grants from the Academy of Finland and The Tor, Joe \& Pentti Borg Foundation. We thank Mrs Tea Sundqvist, Mr Timo Seppälä and Mr Raimo Mäkinen for valuable assistance.

\section{References}

Berndtson, W.E. (1977) Methods for quantifying mammalian spermatogenesis: a review. J. Anim. Sci. 44, $818-833$.
Charny, C.W. (1940) Testicular biopsy; its value in male sterility. J. Am. med. Assoc. 115, 1429-1432.

Colgan, T.J., Bedard, Y.C., Strawbridge, H.T.G., 
Buckspan, M.B. \& Klotz, P.G. (1980) Reappraisal of the value of testicular biopsy in the investigation of infertility. Fert. Steril. 33, 56-60.

Hotchkiss, R.S. (1942) Testicular biopsy in the diagnosis and treatment of sterility in the male. Bull. N.Y. Acad. Med. 18, 600-605.

Johnsen, S.G. (1970) Testicular biopsy score count-a method for registration of spermatogenesis in human testes: normal values and results in 335 hypogonadal males. Hormones 1, 2-25.

Leong, A.S.-Y. \& Matthews, C.D. (1982) The role of testicular biopsy in the investigation of male infertility. Pathology 14, 205-210.

Levin, H.S. (1979) Testicular biopsy in the study of male infertility. Its current usefulness, histologic techniques, prospects for the future. Hum. Pathol. 10, 569-584.

Nseyo, U.O., Englander, L.S., Huben, R.P. \& Pontes, J.E. (1984) Aspiration biopsy of the testis: another method for histologic examination. Fert. Steril. 42 , 281-284.

Onstad, O. (1967) Studies on postnatal testicular changes, semen quality, and anomalies of reproductive organs in the mink. Acta endocr., Copenh., Suppl. 117, 1-117.

Persson, P.S., Åhren, C. \& Obrant, K.O. (1971) Aspiration biopsy smear of testis in azoospermia. Scand. $J$. Urol. Nephrol. 5, 22-26.
Sundqvist, C. \& Gustafsson, M. (1983) Sperm test-a useful tool in breeding work of mink. J. Sci. agric. Soc. Finl. 55, 119-131.

Sundqvist, C., Lukola, A. \& Valtonen, M. (1984) Relationship between serum testosterone concentrations and fertility in male mink (Mustela vison). J. Reprod. Fert. 70, 409412.

Tauson, A.-H. (1985) Different feeding intensity levels to mink. 1. Effects on male reproductive performance. Swedish J. Agric. Res. 15, 77-85.

Tung, K.S.K. \& Alexander, N.J. (1977) Autoimmune reactions in the testis. In The Testis, Vol. IV, pp. 491-516. Eds A. D. Johnson \& W. R. Gomes. Academic Press, New York.

Tung, K.S.K., Ellis, L., Teuscher, C., Meng, A., Blaustein, J., Kohno, S. \& Howell, R. (1981) The black mink (Mustela vison). A natural model of immunologic male infertility. J. exp. Med. 154, 1016-1032.

Tung, K.S.K., Ellis, L.E., Childs, G.V. \& Dufau, M. (1984) The dark mink: a model of male infertility. Endocrinology 114, 922-929.

Wong, T.-W., Straus, F.H. \& Warner, N.E. (1973) Testicular biopsy in the study of male infertility. I. Testicular causes of infertility. Arch. Pathol. 95, 151-159. 